\title{
Frozen Shoulder: Current Concept of Management
}

\author{
Tito Sumarwoto ${ }^{1}$, Seti Aji Hadinoto ${ }^{1}$, Musa Fasa Roshada ${ }^{2 *}$ \\ ${ }^{1}$ Department of Orthopaedic and Traumatology, Faculty of Medicine, Sebelas Maret University, Prof. Dr. R Soeharso Orthopaedic \\ Hospital, Surakarta, Indonesia; ${ }^{2}$ Department of Orthopaedic and Traumatology, Faculty of Medicine, Sebelas Maret University, \\ Surakarta, Indonesia
}

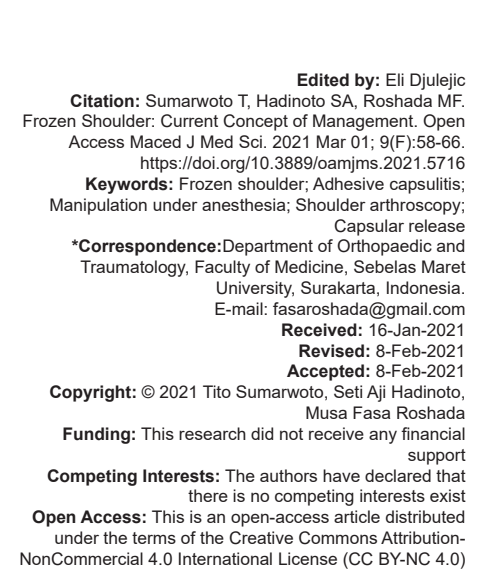

Introduction

Frozen shoulder is a disorder of musculoskeletal tissue around the shoulder resulting from prolonged inflammation particularly in subsynovial layer of the capsule, thus it is also termed as adhesive capsulitis $(A C)$. The chronic inflammation persisted for more than 3 months, accompanied with thickening of the capsule, progressive fibrosis, and contracture of capsule in glenohumeral joint. The characteristic sign was scapulohumeral pain with loss of active and passive motion [1], [2]. The underlying mechanism of $A C$ remains unclear; however, a theory has been proposed that there is an involvement of growth factors such as transforming growth factor-beta that plays a role in fibrotic cascade and stimulates synovitis development [1]. AC prevalence was $2 \%-5 \%$ of general population, with females 4 times more often affected than men. Patients mostly affected age is 40 to 60 years old, and it more often affect the nondominant hand. Around 20\%-30\% patients will develop the condition on the contralateral side [3], [4]. A recent meta-analysis study by Prodromidis and Charalambous suggested genetic factors to frozen shoulder, noting a higher likelihood of this disease to affect Caucasian race, and those with a positive family history [5].
Primary $A C$ is a term used to describe the idiopathic process of global capsular inflammation and fibrosis occurring in the absence of other lesions. Secondary $A C$ is a term used to describe a shoulder pain and loss of range with another underlying lesion. Although the etiology of $A C$ has not been identified, there are a number of associated risk factors [6]. Comorbidities such as diabetes mellitus and hypothyroidism are strongly associated with AC. Having first degree relative with $A C$ is also a risk factor of this condition [7], [8].

\section{Pathophysiology}

AC has been known to be a predominantly fibrotic disease comparable to Dupuytren's disease since fibroblasts mixed with type I and type III collagen are primarily seen in the histology of affected specimens. These fibroblasts have been found to turn into a phenotype of smooth muscle (myofibroblasts), which is thought to be responsible for capsular contracture. There are altered amounts of matrix metalloproteinases (MMPs) involved in the remodeling of scar tissue. MMP-14, for instance, is expressed in control patients, 
but not at all in AC patients [2]. MMP-2 is activated by MMP-14, they are involved in degradation of collagen and this may lead to more production of collagen compared to its breakdown. There is a decrease in expression of MMP-1 and MMP-2 in frozen shoulder patients. This was accompanied with the tissue inhibitor of metalloproteinase expression. These results support the statement that the product of an imbalance between extracellular matrix tissue deterioration, remodeling, and regeneration results in AC. Future research may focus on the therapy that inhibit fibrogenesis directly or promote fibrotic tissue remodeling [9].

It is now widely recognized that an inflammatory and fibrotic mechanism is involved in the production of AC. This is corroborated by studies showing elevated inflammatory cytokines in capsular and bursal tissues of patients with $A C$, including interleukin (IL)-1a, IL-1b, tumor necrosis factor-a, and cyclooxygenase (COX)-1 and COX-2 relative to controls. It could, therefore, be argued that $\mathrm{AC}$ is mainly an inflammatory mechanism that ultimately contributes to fibrotic shift inflammatory cells, including T cells, B cells, macrophages and mast cells, are present in almost all of the samples collected from the rotator interval of patients with AC [10]. Mast cells are known to control in vivo fibroblast proliferation and may serve as an intermediate between the inflammatory and subsequent fibrotic processes [2].

\section{Diagnosis}

\section{Physical examination}

\section{Look}

At first look of the patient, undressing the patient is needed to compare the affected site with the healthy site. In early stage, there usually no apparent abnormality found. However, any visible scars indicating prior surgery or trauma that constitute as risk factors for frozen shoulder should be look upon in the physical examination. In later stage, muscle atrophy can be founded as a result of chronic decrease of movement of the frozen shoulder.

\section{Feel}

With palpation, common findings include tenderness over deltoid insertion. With deep palpation, tenderness may be felt over anterior and or posterior capsule.

\section{Move}

Range of motion (ROM) is crucial in diagnosing frozen shoulder. Forward flexion, abduction, and internal and external rotation are better assessed in supine condition with considering the scapulothoracic movement. In frozen shoulder, there is usually a true mechanical restriction with passive movement at certain point that is reproducible and must be differentiated from restricted of movement due to pain, this finding is a result of capsular contracture around the shoulder [10], [11].

Typically, patients experience shoulder pain and everyday movement restrictions due to loss of range of movement. Usually insidious, the onset of pain appears to be more gradual than in other shoulder disease. The origin of the deltoid is usually painful. Night pain is usually observed, and the pain was aggravated when patient lying onto the affected side thus usually was avoided [12] Pain that was stimulated by repetitive overhead activities is predictive of other diseases rather than frozen shoulder. Pain will be aggravated when the shoulder is pushed outside the limits permitted by the contracted capsule; pain can be decreased with rest [6], [11]. Loss of motion follows the onset of pain and along with disease progression, usually becomes more pronounced. Loss of ROM may manifest itself as difficulty dressing and combing, and difficulty reaching the back pocket. Motion loss becomes extreme at an early stage and affects movement in all directions [10], [13].

\section{Radiological examination}

\section{Plain radiographs}

The main goal of simple radiographs is in their ability to distinguish between primary $A C$ and glenohumeral arthritis or calcific tendinosis as differential diagnosis. With $A C$ due to disuse and the inflammatory process, osteopenia that occurs over a short time can be seen. Otherwise, simple film images are mostly of little use in the sense of AC [2].

\section{Ultrasound}

In diagnosing $\mathrm{AC}$, ultrasound has many benefits. Ultrasound is easy to obtain, inexpensive, quick, and enables the examiner at the time of evaluation to compare sonographic findings with clinical signs, such as tenderness to test over the glenohumeral joint and reduced ROM. Increased vascular flow and thickening of the rotator interval structures are the specific findings of $A C$ during ultrasound inspection. Ultrasound may also find effusion of biceps tendon sheats [14], [15], [16]. In the majority of shoulders, tests of coracohumeral ligament ( $\mathrm{CHL}$ ) thickness can be carried out and thickening can be indicative of $A C$. The existence in the rotator interval of a hypoechoic area with increased vascularity correlates with the presence of fibrovascular inflammatory tissue that can provide early and precise diagnosis [14], [15], [16], [17]. 
Magnetic resonance imaging $(M R I) /$ magnetic resonance arthrography (MRA)

$M R I$ is considered the routine modality for $A C$ as a non-invasive examination, especially in patients with less serious clinical symptoms who may be misdiagnosed with rotator cuff tears, bursitis, or other conditions [2]. MRI may detect changes in the synovium and joint capsule and can exclude other shoulder pathologies that resemble AC such as rotator cuff tear, tendinitis, osteoarthritis, subacromial impingement, and occult fracture. The hallmark MRI results of $A C$ are the axillary pouch's thickening and oedematous appearance [18], [19].

The discrepancy between MRI and MRA lies in the sensitivity of $\mathrm{CHL}$ thickness and enhancement of the rotator interval, with greater sensitivity given by MRA [2]. A study also showed that intravenous administration of contrast agents (i.e., indirect MRA) can be helpful in identifying enhancement of capsular and synovial structures associated with ongoing inflammation. To detect pathology over the rotator cuff interval, MRA may also be used [17], [20], [21]. Thickening of the CHL and capsule has high specificity but low sensitivity for the diagnosis of $A C$ at the rotator cuff interval [22].

The use of MRI or MRA as the gold standard for the diagnosis of $A C$ has been stated in some studies. However, as early AC has unfavorable MR results, there is no agreement or consensus on the gold standard for the diagnosis of $A C$ or frozen shoulder [17].

\section{Computed tomography (CT) angiography}

The ability of CT arthrography in AC diagnosis has been researched in one study. Thickening of the axillary pouch was observed by CT arthrography in the setting of $A C$, consistent with previously recorded results on MRI and MRA. Cerny et al. found sensitivities of $100 \%$ and $81 \%$ and specificities of $75 \%$ and $85 \%$, respectively, using cutoff values of $4 \mathrm{~mm}$ for the medial wall and $4.9 \mathrm{~mm}$ for the lateral wall [23].

With short examination time and patient irradiation held as low as possible to provide adequate diagnostic quality imaging, CT arthrography represents a valuable and more usable image modality for MRI and MRA [23].

\section{Differential diagnosis}

The differential diagnosis for the patient who presents with a stiff and painful shoulder is extensive. Differential diagnosis such as calcific tendonitis, bicipital tenosynovitis, glenohumeral and acromioclavicular arthritis, and tears of the rotator cuff can lead to a stiff and painful shoulder, and limitation of ROM and should be ruled out with physical and radiological examination [1], [24].
We have to take into consideration that the clinical feature may also be as a result of secondary frozen shoulder. Other secondary causes are rare, but the likelihood of infection or tumor and prompt urgent investigation should be increased by indications such as weight loss, systemic upset, shoulder swelling, and bony tenderness [25].

\section{Classification}

There are four AC stages (Summarized in Table 1). With arthroscopy and biopsy, each step can vary from each other. It may be difficult to differentiate stage one $A C$ from other shoulder diseases because the symptoms are not clear. A progressive onset of pain usually referred to the deltoid insertion is characteristic in stage one. Typically, it is achy at rest and sharper with motion. It is normal to find pain at night, and patients often report an inability to sleep on the affected side. In general, the duration of symptoms is $<3$ months. Capsular pain can also be found with deep palpation or passive stretching. At the poles of motion, there is a hollow final sensation. Patients can report mobility limitations, but under anesthesia, motion is completely restored [1]. Under arthroscopy, there was fibrinous synovial inflammatory reaction with no presence of adhesion or formation of contracture. Histologically, there was still rare inflammatory cells, hypervascular, and hypertrophic but the capsular tissue is still normal [6], [24].

Stage 2, also called freezing stage, represents a combination of acute synovitis and progressive capsular contracture. The pain persists and, particularly at night, is more intense. In forward flexion, abduction, and internal and external rotation, motion is limited. Motion restriction is improved with intraarticular anesthetic injection, but cannot be completely reversed. To differentiate between the first 2 steps, intra-articular anesthetic injection is necessary [1]. Stage 2 frozen shoulder's arthroscopy will show synovium proliferation and early adhesion formation. It also shows the appearance of the Christmas tree, which is characterized as thickened, hypervascular synovitis. In this process, early loss of the dependent axillary pouch causes restricted motion. Hypertrophic, hypervascular synovitis with perivascular and subsynovial scar formation could be identified during capsular biopsy [1], [24].

The prevailing patient complaint is profound stiffness in Stage 3, also referred to as the frozen stage. In the final ROM and sometimes at night, pain can still be present. Physical analysis shows a feeling of substantial loss of mobility at the ends of movement and tethering. With intra-articular anesthetic injection or examination under anesthesia, no change in motion is observed. Symptoms at this stage have usually been present for 9-15 months [1]. Step 3 arthroscopic testing shows less synovitis and more fibrosis. Besides axillary 
fold loss, there is minimal synovitis. Capsular biopsy reveals that hypercellular collagenous tissue with a thin synovial layer exhibits similar characteristics to other conditions of fibrosis [1], [24].

Stage 4, also called the thawing stage, patient usually feels minimal pain with profound stiffness. Significant motion loss is commonly observed, but gradual improvement in motion can occur. Arthroscopy of Stage $4 \mathrm{AC}$ demonstrates fully mature adhesions, making it difficult to identify intra-articular structures. There is no report on capsular histopathology of AC [1], [24].

\section{Management}

Current management of $A C$ includes nonoperative and operative management (See algorithm in Figure 1). Non-operative management of AC includes oral anti-inflammatory medication nonsteroidal antiinflammatory drug (NSAIDs), shoulder injections with corticosteroids or hyaluronate, hydrodilation, physical therapy, electrotherapy, cryotherapy, or any combination of this management [26]. Operative management of $A C$ could be done by either manipulation under anesthesia (MUA), arthroscopic capsular release, or open capsular release [27], [28], [29]. When a strategic attempt at conservative management has failed, operative management for frozen shoulder is commonly considered. To continue surgery, there is no discrete timeline. Patients should have engaged in some form of physiotherapy for at least 4-6 months as a general rule and have shown little or no improvement. In the freezing phase, which is the painful phase of the disease process, a more cautious approach is largely prescribed for patients. Surgical intervention is then really considered when patients started to feel that they have no improvement of symptoms and have occupational, recreational, or sleep restrictions [30].

\section{Non-operative management}

\section{NSAID}

NSAIDs are often prescribed in the early inflammatory phases of $A C$ to provide short-term pain relief. Both COX-1 and COX-2 expressions are elevated in capsular and bursal tissues of patients with $\mathrm{AC}$, and these anti-inflammatory agents target synovitis as the source of pain [2]. Pain management is a key feature to allow patients to tolerate physical therapy needed to improve ROM. Oral corticosteroids can also be prescribed and have been shown to improve pain, especially night pain, and ROM in the short-term, but similar to NSAIDs, they do not have a substantial effect on recovery [2], [27].

\section{Intra-articular corticosteroid injection}

Corticoids in the treatment of AC may lead to a faster increase of ROM and pain reduction [31], [32]. Furthermore, intra-articular corticosteroid injection provides faster and better improvement in symptoms relieves compared to oral steroid treatment [33], [34]. Intra-articular steroid injection decreases fibromatosis and myofibroblasts in AC [35], [36], [37]. An intraarticular injection of long-acting anesthetic and glucocorticoid could be useful for exacerbate symptoms after exercise. Intra-articular corticosteroid injections led to fast pain relief and improved ROM after 4 weeks of treatment [27], [38], [39].

\section{Hyaluronate intra-articular injection}

Sodium hyaluronate is an unbranched polysaccharide which has chondroprotective effect. It has been shown to provide equivalent outcomes to intraarticular corticosteroid injection [40]. Pharmacologically, hyaluronate has metabolic effects on articular cartilage, synovial tissue, and synovial fluid. Hyaluronate intra-articular injection leads to a lower coefficient of enhancement in the synovium, which is a measurement for synovitis on patients with AC [2], [27], [41].

\section{Hydrodilation}

Hydrodilation is a procedure performed by injection of air or fluid under fluoroscopy with local anesthetic to raise the intracapsular volume and pressure, and stretch the contracted capsule until capsular breakup, also known as distention arthrography or brisement. Under local anesthetic, hydrodilation can be performed and takes about $15 \mathrm{~min}$ to complete. Various fluids have been used and in combination with arthrography [1], [2], [42].

\section{Physical therapy}

The widely recommended treatment for avoiding capsular contracture and improving the ROM in the advanced stages of the disease is physical therapy. Despite omnipresent usage, supporting evidence to show its advantage is very few [43]. Physical therapy should not be aggressive or painful, and as the purpose of physical therapy is to increase the ROM, strengthening is rarely required. In most cases, gentle, progressive stretching is successful. Patients should, however, be told that they will have a lengthy recovery time [11], [28].

\section{Electrotherapy}

Modalities of electrotherapy, also known as electrophysical agents, are forms of physical therapy aimed at reducing discomfort and enhancing function in 
the body through an increase in electrical, sound, light, or thermal energy. Therapeutic ultrasound, low-level laser therapy, interference current, transcutaneous electrical nerve stimulation, and pulsed electromagnetic field therapy are used in electrotherapy. In practice, patients with frozen shoulder typically undergo an electrotherapy mixture and other physical therapy treatment regiment [11], [44], [45].

\section{Cryotherapy}

Whole-body cryotherapy (WBC) requires unclothed body exposure in a chamber that circulates very cold air sustained for 2 to $3 \mathrm{~min}$ between $-110^{\circ} \mathrm{C}$ and $-140^{\circ} \mathrm{C}$. It is believed that WBC provides the body with anti-inflammatory and analgesic effects. Ma et al. compared physical therapy alone with WBC versus physical therapy, noting that using the American Shoulder and Elbow Surgeons Standardized Shoulder Assessment Form, the group receiving physical therapy with WBC showed higher improvement in visual analog scale, active ROM (flexion, abduction, internal rotation, and external rotation), and self-assessed functional score [2], [46].

\section{Operative management}

For those failing conservative treatment with significant pain, only then surgical treatment should be considered. There is no general consensus or recommendation on the time frame of when to do surgery. However, generally surgical option is considered when conservative treatments showed no improvement for 12 months and patient still presents with debilitating signs and symptoms. Patients who do not have any improvement with physical therapy should be looked for another underlying pathology such as rotator cuff tear or osteoarthritis. The surgical treatments of frozen shoulder that will be described in this article include MUA, arthroscopic capsular release, and capsular distention [47].

\section{MUA}

MUA is a popular technique that is routinely performed for patients with frozen shoulder that shows no improvement of pain and stiffness for 6 months. The long-term outcome of this non-invasive treatment is well researched and good in the majority of patients, even the improvement of ROM is sustained after 15 years of follow-up [6].

Patient's position is usually supine and with the combination of general anesthesia and block of interscalene nerve. At first, affected shoulder is moved passively and is recorded as pre-operative ROM. The surgeon holds the patients upper arm with his hand near to axilla and his forearm against the patient's arm, the contralateral hand of the surgeon stabilizes the scapula superiorly to form a very short lever arm. Then, the arm of the patient is elevated in the plane of scapula until an audible tearing sound is heard from the inferior capsule. At this step, when patients arm is fully elevated it should also be in full external rotation to continue the tearing of anterior capsule. To tear the posterior capsule, patient's arm is then adducted across patient's chest and then held in internal rotation and adducted across the body to continue and complete the tearing of superior and posterior capsule. After completion of shoulder manipulation, shoulder joint is injected with $40 \mathrm{mg}$ of methylprednisolone and $10 \mathrm{ml}$ of $0.25 \%$ bupivacaine. Physiotherapy should follow immediately and a full range of active and passive movement is encouraged [48], [49].

In more resistant shoulder pain and contracture of post-traumatic and frozen shoulder after surgery, closed manipulation should not be performed as the risk of fracture is increased [1], [24]. As a result of unnecessarily forceful manipulation, multiple complications can occur, such as glenohumeral dislocation, iatrogenic humerus fractures, rotator cuff tear, labral tears, brachial plexus injuries, and hemorrhagic effusions and hematomas, which can be harmful to articular cartilage [24]

\section{Arthroscopic capsular release}

Capsular release under arthroscopy has been known as an effective and safe method for the treatment of frozen shoulder. Arthroscopy is both diagnostic and for therapeutic as it has the ability to directly visualize the $\mathrm{CHL}$ whether it is tightened, inspect the rotator cuff, and to see whether there is contracture of the capsule then it is as well is able to perform capsulotomy and ensure adequate release of the capsule [6]. The standard capsulotomy that is performed in arthroscopy is anteroinferior capsular release. The release of posterior capsule, however, is controversial. Arthroscopic capsular release is seen superior to MUA as it directly visualize the joint, it has the ability to confirm the diagnosis and exclude the risk of blind MUA. Multiple studies also found that arthroscopic capsular release has better outcome in term of pain relief and functional improvement in comparison to MUA [2], [50], [51].

The procedure is performed with the patient in beach chair position. Posterior portal may be hampered by severe capsular contracture. In which case, a simple maneuver of forward elevation can loosen the joint and help to insert the arthroscope. Anterior portal is used as the insertion of electrocautery to perform capsulotomy or release the anterior capsule and rotator interval. The main lesion in frozen shoulder is the tightened $\mathrm{CHL}$ and rotator interval and its contracted capsule. The release should include all rotator interval tissue between the upper subscapularis and the superior glenohumeral 
Table 1: Staging of frozen shoulder [1], [5], [20].

\begin{tabular}{|c|c|c|c|c|}
\hline Characteristics & Inflammation Phase & Freezing Phase & Frozen Phase & Thawing Phase \\
\hline Pain & + & +++ & +- & - \\
\hline Stiffness & - & + & +++ & ++ \\
\hline ROM & Fully restored under anesthesia & Not fully restored under anesthesia & No improvement under anesthesia & Little ROM improvement \\
\hline Arthroscopy & Fibrinosus inflammatory reaction & Early formation of adhesion & Less synovitis, more fibrosis & Mature adhesion \\
\hline
\end{tabular}

ROM: Range of motion

ligament with preservation of the medial sling of biceps. The release is then continued to middle glenohumeral ligament continued with the release of anterior and inferior capsule [30].

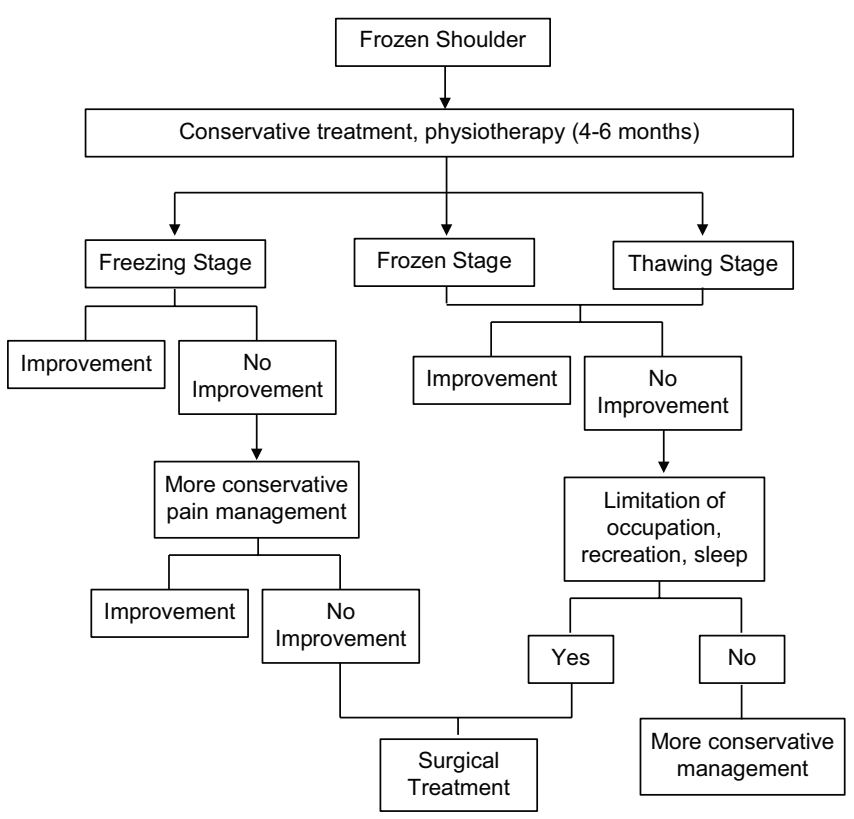

Figure 1: Frozen shoulder management algorithm [30]

When the region between the capsule and the tendon subscapularis is detected, the electrocautery use is stopped and is often stopped before the lower border of the subscapularis in consideration of the axillary nerve near the structure. To extend the release into the axillary recess, an arthroscopic biter is used and should stop at the 6 o'clock position. In the sub-acromial space, the arthroscope is then positioned. Whenever present, subacromial adhesions should be released by the lateral portal to provide a more controlled release. The shoulder is then taken into external rotation and abduction after the anterior and anterior-inferior releases, accompanied by internal rotation to confirm the extent of the release [1], [6].

Passive, assisted-active exercises, and stooping exercise for forward flexion and external rotation were started with the aid of a physical therapist 1 day following surgery as a post-operative recovery protocol. Patients started active ROM to reinforce the rotator cuff and scapular stabilizers following 2 weeks of passive ROM exercise. After 4-6 weeks of rehabilitation protocol, the patients should return to normal daily routines without strict limitation. To achieve maximum muscle control of the shoulder, rehabilitation protocol should continue for 3 months following surgery [52].

\section{Open capsular release}

Open surgical release for frozen shoulder is now rarely performed and served as the last option as the indication of it is very limited. However, it should still be put into consideration for patients failing capsular release with manipulation. Open surgical release is mostly considered for those with frozen shoulder secondary to traumatic event or following previous surgical procedure around the shoulder involving hardware used as in open reduction and internal fixation [11], [24].

The procedure is performed with an incision over the clavicle to the lateral border of coracoid. To expose and release the $\mathrm{CHL}$, deltoid muscle is split and the $\mathrm{CHL}$ is excised with externally rotate the patients arm. Identification of the rotator interval border is done along with identification of long head of biceps. The release should include the tissue between the subscapularis and supraspinatus and below the coracoid. Commonly injured muscle during this procedure is subscapularis, supraspinatus, and long head of biceps thus identification of this structure during the procedure is important. The release can be extended when external rotation evaluation remains tight. It includes the middle glenohumeral ligament, inferior glenohumeral ligament, and the capsule as far posteriorly as possible. However, for sufficient visualization, this can be difficult and may require subscapularis tenotomy and repair. The superior and posterior capsule in frozen shoulder has little involvement and the release of this capsule is more often not necessary for the treatment of idiopathic frozen shoulder [24].

Postoperatively, patients' arm is supported with roller towel and the arm is held in external rotation. It has to be remembered that the arm should not be held in a sling as this may force and immobilize the arm in internal rotation. The next day, patient is trained to exercise shoulder ROM by the help of physiotherapist and may be discharged and trained is continued to preserve the movement improvement following the surgery [20].

\section{Prognosis}

In most cases of idiopathic frozen shoulder, spontaneous recovery to normal level is expected and conservative treatment usually succeeds in most cases. However, for patient with resistant cases and those with 
comorbidities such as diabetes mellitus, or bilaterally affected, they would have better outcome with early operative treatment [53].

\section{Conclusion}

Frozen shoulder or $\mathrm{AC}$ is common and can be diagnosed from physical examination alone whereas supporting examination can be performed to help the diagnosis and to exclude differential diagnosis or accompanying condition. Most of the cases resolve spontaneously thus conservative treatment should be the first choice of frozen shoulder. However, for cases that failed with conservative treatment and had a debilitating effect to patient's daily life or cases with history of surgery, operative treatment should be considered. Operative management is aimed to release the capsule either by MUA, by arthroscopy, or by open surgery. Physical rehabilitation following every procedure is mandatory and key to maintain ROM years following the surgery.

\section{References}

1. Neviaser AS, Hannafin JA. Adhesive capsulitis: A review of current treatment. Am J Sports Med. 2010;38(11):2346-56. https://doi.org/10.1177/0363546509348048

\section{PMid:20110457}

2. Le HV, Lee SJ, Nazarian A, Rodriguez EK. Adhesive capsulitis of the shoulder: Review of pathophysiology and current clinical treatments. Shoulder Elbow. 2017;9(2):75-84. https://doi. org/10.1177/1758573216676786

PMid:28405218

3. Walmsley S, Osmotherly PG, Rivett DA. Clinical identifiers for early-stage primary/idiopathic adhesive capsulitis: Are we seeing the real picture? Phys Ther. 2014;94(7):968-76. https:// doi.org/10.2522/ptj.20130398

PMid:24652474

4. White D, Choi H, Peloquin C, Zhu Y, Zhang Y. Secular trend of adhesive capsulitis. Arthritis Care Res (Hoboken) 2011;63(11):1571-5. https://doi.org/10.1002/acr.20590 PMid:22034118

5. Prodromidis AD, Charalambous CP. Is There a Genetic Predisposition to Frozen Shoulder?: A Systematic Review and Meta-Analysis. JBJS Rev. 2016 Feb 23;4(2):01874474201602000-00004. doi: 10.2106/JBJS.RVW.0.00007. PMID: 27490134.

6. Neviaser AS, Neviaser RJ. Adhesive capsulitis of the shoulder. J Am Acad Orthop Surg. 2011;19(9):536-42.

PMid:21885699

7. Wang K, Ho V, Hunter-Smith DJ, Beh PS, Smith KM, Weber AB. Risk factors in idiopathic adhesive capsulitis: $A$ case control study. J Shoulder Elbow Surg. 2013;22(7):e24-9. https://doi. org/10.1016/j.jse.2012.10.049

PMid:23352186
8. Zreik NH, Malik RA, Charalambous CP. Adhesive capsulitis of the shoulder and diabetes: A meta-analysis of prevalence. Muscles Ligaments Tendons J. 2016;6(1):26-34. https://doi. org $/ 10.32098 / \mathrm{mltj} .01 .2016 .04$

9. Lubis AM, Lubis VK. Matrix metalloproteinase, tissue inhibitor of metalloproteinase and transforming growth factor-beta 1 in frozen shoulder, and their changes as response to intensive stretching and supervised neglect exercise. J Orthop Sci. 2013;18(4):519-27. https://doi.org/10.1007/s00776-013-0387-0 PMid:23604641

10. Kelley MJ, Shaffer MA, Kuhn JE, Michener LA, Seitz AL, Uhl TL, et al. Shoulder pain and mobility deficits: Adhesive capsulitis: Clinical practice guidelines linked to the international classification of functioning, disability, and health from the orthopaedic section of the American physical therapy association. J Orthop Sports Phys Ther. 2013;43(5):A1-31. https://doi.org/10.2519/jospt.2013.0302

11. Feeley SM, Larson ES, Diduch DR. Adhesive capsulitis: Current concepts. Ann Sports Med Res. 2017;4(6):1124.

12. Manske RC, Prohaska D. Clinical commentary and literature review: Diagnosis, conservative and surgical management of adhesive capsulitis. Shoulder Elbow. 2010;2(4):238-54. https:// doi.org/10.1111/j.1758-5740.2010.00095.x

13. Manske RC, Prohaska D. Diagnosis and management of adhesive capsulitis. Curr Rev Musculoskelet Med. 2008;1(34):180-9. https://doi.org/10.1007/s12178-008-9031-6 PMid: 19468904

14. Wu YT, Ho CW, Chen YL, Li TY, Lee KC, Chen LC. Ultrasoundguided pulsed radiofrequency stimulation of the suprascapular nerve for adhesive capsulitis: A prospective, randomized, controlled trial. Anesth Analg. 2014;119(3):686-92. https://doi. org/10.1213/ane. 0000000000000354 PMid:25010824

15. Yoong P, Duffy S, McKean D, Hujairi NP, Mansour R, Teh JL. Targeted ultrasound-guided hydrodilatation via the rotator interval for adhesive capsulitis. Skeletal Radiol. 2015;44(5):7038. https://doi.org/10.1007/s00256-014-2047-7

16. Walmsley S, Osmotherly PG, Walker CJ, Rivett DA. Power Doppler ultrasonography in the early diagnosis of primary/ idiopathic adhesive capsulitis: An exploratory study. J Manipulative Physiol Ther. 2013;36(7):428-35. https://doi. org/10.1016/j.jmpt.2013.05.024 PMid:23830711

17. Harris G, Bou-Haidar P, Harris C. Adhesive capsulitis: Review of imaging and treatment. J Med Imaging Radiat Oncol. 2013;57(6):633-43. https://doi.org/10.1111/1754-9485.12111 PMid:24283550

18. Gokalp G, Algin O, Yildirim N, Yazici Z. Adhesive capsulitis: Contrast-enhanced shoulder MRI findings. J Med Imaging Radiat Oncol. 2011;55(2):119-25. https://doi. org/10.1111/j.1754-9485.2010.02215.x PMid:21501399

19. Zhao W, Zheng X, Liu Y, Yang W, Amirbekian V, Diaz LE, et al. An MRI study of symptomatic adhesive capsulitis. PLoS One. 2012;7(10):e47277. https://doi.org/10.1371/journal. pone.0047277 PMid:23082152

20. Song KD, Kwon JW, Yoon YC, Choi SH. Indirect MR arthrographic findings of adhesive capsulitis. AJR Am J Roentgenol. 2011;197(6):1105-9. https://doi.org/10.2214/ ajr.10.6099

PMid:22109326

21. Ahn KS, Kang $\mathrm{CH}$, Oh YW, Jeong WK. Correlation between magnetic resonance imaging and clinical impairment in patients with adhesive capsulitis. Skeletal Radiol. 2012;41(10):1301-8. 
https://doi.org/10.1007/s00256-012-1391-8

PMid:22430562

22. Zappia M, di Pietto F, Aliprandi A, Pozza S, de Petro P, Muda A et al. Multi-modal imaging of adhesive capsulitis of the shoulder. Insights Imaging. 2016;7(3):365-71. https://doi.org/10.1007/ s13244-016-0491-8

PMid:27107871

23. Cerny $M$, Omoumi $P$, Larbi A, Manicourt D, Perozziello A, Lecouvet $\mathrm{F}$, et al. CT arthrography of adhesive capsulitis of the shoulder: Are MR signs applicable? Eur J Radiol Open. 2017;4:40-4. https://doi.org/10.1016/j.ejro.2017.03.002 PMid:28409175

24. Hsu JE, Anakwenze OA, Warrender WJ, Abboud JA. Current review of adhesive capsulitis. J Shoulder Elbow Surg. 2011;20(3):502-14. https://doi.org/10.1016/j.jse.2010.08.023 PMid:21167743

25. Robinson CM, Seah KT, Chee $\mathrm{YH}$, Hindle P, Murray IR. Frozen shoulder. J Bone Joint Surg Br. 2012;94(1):1-9. PMid:22219239

26. Griggs SM, Ahn A, Green A. Idiopathic adhesive capsulitis. J Bone Joint Surg Am Vol. 2000;82(10):1398-407.

27. Yip M, Francis AM, Roberts T, Rokito A, Zuckerman JD, Virk MS. Treatment of Adhesive capsulitis of the shoulder: A critical analysis review. JBJS Rev. 2018;6(6):e5. https://doi. org/10.2106/jbjs.rvw.17.00165

PMid:29916942

28. Levine WN, Kashyap CP, Bak SF, Ahmad CS, Blaine TA, Bigliani LU. Nonoperative management of idiopathic adhesive capsulitis. J Shoulder Elbow Surg. 2007;16(5):569-73. https:// doi.org/10.1016/j.jse.2006.12.007

PMid: 17531513

29. Rill BK, Fleckenstein CM, Levy MS, Nagesh V, Hasan SS. Predictors of outcome after nonoperative and operative treatment of adhesive capsulitis. Am J Sports Med. 2011;39(3):567-74. https://doi.org/10.1177/0363546510385403 PMid:21160014

30. Sharma S, Jacobs L. Management of frozen shoulderconservative vs surgical? Ann $\mathrm{R}$ Coll Surg Engl. 2011;93(5):343-4.

PMid:21943454

31. Blanchard V, Barr S, Cerisola FL. The effectiveness of corticosteroid injections compared with physiotherapeutic interventions for adhesive capsulitis: A systematic review. Physiotherapy. 2010;96(2):95-107. https://doi.org/10.1016/j. physio.2009.09.003 PMid:20420956

32. de Carli A, Vadalà A, Perugia D, Frate L, lorio C, Fabbri M, et al. Shoulder adhesive capsulitis: Manipulation and arthroscopic arthrolysis or intra-articular steroid injections? Int Orthop. 2012;36(1):101-6. https://doi.org/10.1007/s00264-011-1330-7 PMid:21833684

33. Song A, Higgins LD, Newman J, Jain NB. Glenohumeral corticosteroid injections in adhesive capsulitis: A systematic search and review. PM R. 2014;6(12):1143-56. https://doi. org/10.1016/j.pmrj.2014.06.015 PMid:24998406

34. Shin SJ, Lee SY. Efficacies of corticosteroid injection at different sites of the shoulder for the treatment of adhesive capsulitis. J Shoulder Elbow Surg. 2013;22(4):521-7. https://doi. org/10.1016/j.jse.2012.06.015

PMid:22999847

35. Yoon SH, Lee HY, Lee HJ, Kwack KS. Optimal dose of intraarticular corticosteroids for adhesive capsulitis: A randomized, triple-blind, placebo-controlled trial. Am J Sports Med.
2013;41(5):1133-9. https://doi.org/10.1177/0363546513480475 PMid:23507791

36. Roh YH, Yi SR, Noh JH, Lee SY, Oh JH, Gong HS, et al. Intra-articular corticosteroid injection in diabetic patients with adhesive capsulitis: A randomized controlled trial. Knee Surg Sports Traumatol Arthrosc. 2012;20(10):1947-52. https://doi. org/10.1007/s00167-011-1776-6

PMid:22113218

37. Lorbach O, Kieb M, Scherf C, Seil R, Kohn D, Pape D. Good results after fluoroscopic-guided intra-articular injections in the treatment of adhesive capsulitis of the shoulder. Knee Surg Sports Traumatol Arthrosc. 2010;18(10):1435-41. https://doi. org/10.1007/s00167-009-1030-7 PMid:20076945

38. Lorbach O, Anagnostakos K, Scherf C, Seil R, Kohn D, Pape D. Nonoperative management of adhesive capsulitis of the shoulder: Oral cortisone application versus intra-articular cortisone injections. J Shoulder Elbow Surg. 2010;19(2):172-9. https://doi.org/10.1016/j.jse.2009.06.013 PMid:19800262

39. Griesser MJ, Harris JD, Campbell JE, Jones GL. Adhesive capsulitis of the shoulder: A systematic review of the effectiveness of intra-articular corticosteroid injections. J Bone Joint Surg Am. 2011;93(18):1727-33. https://doi.org/10.2106/ jbjs.j.01275

PMid:21938377

40. Lee JH, Kim SB, Lee KW, Lee SJ, Lee JU. Effect of hypertonic saline in intra-articular hydraulic distension for adhesive capsulitis. PM R. 2015;7(7):721-6. https://doi.org/10.1016/j. pmrj.2015.04.013

PMid:25937021

41. Lee LC, Lieu FK, Lee HL, Tung TH. Effectiveness of hyaluronic acid administration in treating adhesive capsulitis of the shoulder: A systematic review of randomized controlled trials. Biomed Res Int. 2015;2015:314120. https://doi.org/10.1155/2015/314120 PMid:25802845

42. Harris JD, Griesser MJ, Copelan A, Jones GL. Treatment of adhesive capsulitis with intra-articular hyaluronate: A systematic review. Int J Shoulder Surg. 2011;5(2):31-7. https://doi. org/10.4103/0973-6042.83194 PMid:21897581

43. Struyf F, Meeus M. Current evidence on physical therapy in patients with adhesive capsulitis: What are we missing? Clin Rheumatol. 2014;33(5):593-600. https://doi.org/10.1007/ s10067-013-2464-3 PMid:24374758

44. Page MJ, Green S, Kramer D, Johnston RV, McBain B, Buchbinder R. Electrotherapy modalities for adhesive capsulitis (frozen shoulder). Cochrane Database Syst Rev. 2016;10:CD011324. cd011324

\section{PMid:25271097}

45. Chen CY, Hu CC, Weng PW, Huang YM, Chiang CJ, Chen CH, et al Extracorporeal shockwave therapy improves short-term functional outcomes of shoulder adhesive capsulitis. J Shoulder Elbow Surg. 2014;23(12):1843-51. https://doi.org/10.1016/j.jse.2014.08.010 PMid:25441567

46. Ma SY, Je HD, Jeong JH, Kim HY, Kim HD. Effects of wholebody cryotherapy in the management of adhesive capsulitis of the shoulder. Arch Phys Med Rehabil. 2013;94:9-16. https://doi. org/10.1016/j.apmr.2012.07.013 PMid:22850489

47. van de Laar SM, van der Zwaal P. Management of the frozen shoulder. In: Orthopedic Research and Reviews. Vol. 6. United Kingdom: Dove Press; 2014. p. 81-90. Available from: https:// 
www.dovepress.com/management-of-the-frozen-shoulderpeer-reviewed-fulltext-article-orr. [Last accessed on 2021 Jan 16]. https://doi.org/10.2147/orr.s71115

48. Tsvieli O, Atoun E, Consigliere P, Polyzois I, Walecka J, Pradhan $\mathrm{R}$, et al. Manipulation under anaesthetic for frozen shoulder using Codman's paradox: A safe and early return of function. Int Orthop. 2018;42(2):339-44. https://doi.org/10.1007/ s00264-017-3558-3

PMid:28699020

49. Kraal T, Beimers L, The B, Sierevelt I, van den Bekerom M, Eygendaal D. Manipulation under anaesthesia for frozen shoulders: Outdated technique or well-established quick fix? EFORT Open Rev. 2019;4(3):98-109. https://doi. org/10.1302/2058-5241.4.180044

PMid:30993011

50. Barnes CP, Lam PH, Murrell GA. Short-term outcomes after arthroscopic capsular release for adhesive capsulitis. J Shoulder Elbow Surg. 2016;25(9):e256-64. https://doi.org/10.1016/j. jse.2015.12.025

PMid:26968090

51. Grant JA, Schroeder N, Miller BS, Carpenter JE. Comparison of manipulation and arthroscopic capsular release for adhesive capsulitis: A systematic review. J Shoulder Elbow Surg. 2013;22(8):1135-45. https://doi.org/10.1016/j.jse.2013.01.010 PMid:23510748

52. Kanbe K. Clinical outcome of arthroscopic capsular release for frozen shoulder: Essential technical points in 255 patients. J Orthop Surg Res. 2018;13(1):56. https://doi.org/10.1186/ s13018-018-0758-5

PMid:29548325

53. Eljabu W, Klinger HM, von Knoch M. Prognostic factors and therapeutic options for treatment of frozen shoulder: A systematic review. Arch Orthop Trauma Surg. 2016;136(1):1-7. https://doi.org/10.1007/s00402-015-2341-4

PMid:26476720 